\title{
Anthropometric Assessment for Adolescent Pregnancy: A Descriptive Study on Married Aadolescents in Bangladesh
}

\section{Haque $\mathrm{MN}^{1}$}

${ }^{1}$ Md. Nuruzzaman Haque, Assistant Professor, Department of Population Science and Human Resource Development, University of Rajshahi, Rajshahi-6205, Bangladesh.

Address for Correspondence: Md. Nuruzzaman Haque. E-mail: nzaman_pop@yahoo.com

\begin{abstract}
Background: Adolescent childbearing has emerged as a major concern in Bangladesh due to its shorter term adverse effects on both the mothers and babies born to adolescent mothers. Bangladesh is one of the vulnerable countries in the world and the most vulnerable country in South Asian region regarding early motherhood risks. Most of the adolescents pelvis is not mature enough for childbirth and malnutrition may stunt normal growth of adolescent women. But a greater proportion of currently married adolescent women want a child very soon. Hence it is needed to assess adolescent women's physical and nutritional status for making future pregnancy outcomes safer. Objectives: This study aims to evaluate the physical and nutritional status of married adolescent women for pregnancy by calculating prevalence of low weight, low height, stunting and thinness. Methodology: For assessing pre-pregnancy physical and nutritional status of married adolescent women, data extracted from Bangladesh Demographic and Health Survey (BDHS)-2004. Based on fundamental anthropometric variables (weight and height), stunting and thinness profile of study population has been prepared. Also, group mean of weight and height, prevalence of low weight $(<45 \mathrm{~kg})$ and low height $(<145 \mathrm{~cm})$ have been calculated. Results: Adolescent women, on average, are at vulnerable for childbirth regarding their weight in the study results. For instance, more than $64 \%$ of married non-pregnant adolescent women's weights are less than $45 \mathrm{~kg}$ and more than $15 \%$ of married non-pregnant adolescent women belong to height less than $145 \mathrm{~cm}$ in Bangladesh. It is also estimated that more than $16 \%$ and around $50 \%$ of married non-pregnant adolescent women were thin and stunted respectively in Bangladesh. Conclusion: Since early childbearing is a social norm in Bangladesh and many of married adolescent women are not physically fit for pregnancy, so it is necessary to encourage married adolescent women to delay childbearing through community education and by encouraging them to use family planning services. It should be necessary to pay special emphasizes for improving adolescent women's nutritional status through the country's Health, Nutrition and Population Sector Program or through National Nutrition Program (NNP).
\end{abstract}

Keywords: Adolescent, Bangladesh, Pregnancy, Stunting, Thinness

\section{Introduction}

$\mathrm{M}$ alnutrition at young age may stunt normal growth of adolescent (aged 10-19 years) women. Early (in adolescence) marriage and early childbirth are social norms in Bangladesh ${ }^{1}$ and $36.4 \%$ and $24.4 \%$ of $10-14$ years aged and 15-19 years aged currently married adolescent women respectively want children very soon (within two years) in Bangladesh ${ }^{2}$. Adolescence is the period of body's developmental process, most of the adolescents' pelvis or birth canal is not mature enough for childbirth in most adolescents. Height and weight are important measures of adolescent's growth and hence weight and height relative to age are important indices for determining the capability of the event of women's pregnancy. The pre-pregnancy minimum standard for weight and height are $45 \mathrm{~kg}$ and $145 \mathrm{~cm}$ respectively ${ }^{3}$. There is a correlation between one's height and pelvic size $^{4}$. Short women are likely to have a small pelvis, which again worsens reproductive outcomes ${ }^{5}$. At 
the time of childbirth, adolescent women's immature pelvis or small birth canal may cause prolonged and/ or obstructed labor. Prolonged (or obstructed) labor is one of the important causes of maternal morbidity and mortality ${ }^{6}$, and also infant morbidity and mortality. About $90 \%$ of pregnancy resulted in live birth (normal or caesarean section) in Bangladesh ${ }^{7}$ but more than 9 percent and 5 percent of adolescent pregnancy resulted as miscarriage and stillbirth respectively as reported by Bangladesh Demographic and Health $2004^{2}$. Bangladesh is one of the vulnerable countries in the world and the most vulnerable country in South Asian region regarding early motherhood risk $^{8,9,10}$. This study aims to assess the physical and nutritional status of married adolescent women in Bangladesh in order to assess adolescent women's physical and nutritional status for making future pregnancy outcomes safer.

\section{Materials and Methods}

\section{Data}

This study is based on secondary data and data extracted from Bangladesh Demographic and Health Survey-2004 (BDHS-2004). The sample for the BDHS2004 covered the entire population residing in private dwelling units in the country, and the BDHS-2004 used a stratified and multi stage cluster sampling method. The BDHS-2004 used four questionnaires (a Household Questionnaire, a Women's Questionnaire, a Men's Questionnaire and a Community Questionnaire). The Women's Questionnaire used to collect information from ever married women of aged 10-49 years. Among the selected household, 11,601 women were identified as eligible for the individual interview and interviews were completed for 11440 of them ${ }^{1}$. Details on the survey procedures and sampling design are available in the main survey report ${ }^{1}$. The data set (of BDHS-2004) for individual women aged 10-49 years ever married women (Individual Recode Data File in SPSS) enriched with various aspects of reproductive health and some basic information (age, residence, etc.) including their weight and height.

After excluding missing cases (for weight and height), this study included 1443 married non-pregnant adolescent women (MNPAW) for assessing their status for pregnancy. Among those 1443 married adolescent women who were non-pregnant at the time of interview, 822 women experienced at least one pregnancy in the preceding 5 years. Some of these pregnancies did not result in live birth, 74 and 46 pregnancies resulted as miscarriage and stillbirth respectively.

To compare married adolescent women's status for pregnancy in different years (i.e. trends in indicators of physical status for pregnancy), data were extracted from Individual Record Data files of BDHS-1996/97, and BDHS-1999/2000 (available at <http://www. measuredhs.com>).

\section{Methods}

The present study focuses on anthropometric variables such as weights, heights, stunting- low height for age, and thinness - low Body Mass Index (BMI) for age, of married adolescent women to examine their status for pregnancy. So, for assessing married adolescent women's status for pregnancy, group mean of weight and height, prevalence of low weight $(<45 \mathrm{~kg})$ and low height $(<145 \mathrm{~cm})$ have been calculated and ruralurban differentials have been tested in the consecutive sections of this study. Also, stunting and thinness profile of study population has been prepared.

\section{Result and Discussion}

\section{Weight and height in adolescence}

Since weight and height relative to age of individuals are used as principal indices for anthropometry, the group mean (including minimum and maximum values) weight (in $\mathrm{kg}$ ) and height (in $\mathrm{cm}$ ) for 13-19 years aged married non-pregnant adolescent women (MNPAW) are provided in Table 1.

Table1: Married non-pregnant adolescent women's (MNPAW's) weight and height- mean and range, Bangladesh, 2004.

\begin{tabular}{|l|l|c|c|c|}
\hline & Indicator & Mean & Min. & Max. \\
\hline \multirow{2}{*}{$\begin{array}{l}\text { MNPAW } \\
(\mathrm{n}=1443)\end{array}$} & Weight $(\mathrm{kg})$ & 43.4 & 23.6 & 73.8 \\
\cline { 2 - 5 } & Height $(\mathrm{cm})$ & 150.2 & 105.7 & 167.7 \\
\hline
\end{tabular}

Source: Author's calculation based on Bangladesh Demographic and Health Survey (BDHS) 2004.

There were differences in weight and height of married non-pregnant adolescent women based on their place of residence (urban and rural). Mean weight and height for age of married non-pregnant adolescent women are shown with place of residence in Table 2. Married non-pregnant adolescent women (MNPAW) who resided in urban areas are heavier (on average in weight) than those MNPAW who resided in rural areas in Bangladesh. But MNPAW who resided in urban areas are shorter (on average) than those who resided in rural areas in Bangladesh.

The group of women with weight and/or height less than the cut-off value (weight $<45 \mathrm{~kg}$ and height $<145 \mathrm{~cm}$ ) may be prone to face obstetric risks during childbirth. It can be easily seen from Table 2 that adolescent women, on an average, at all ages (13-19 years) are at obstetric 
risk category for childbirth regarding their weight but on an average at all ages (13-19 years) they are not at obstetric risk regarding their height.

To look at age specific weight and height status comparing with the cut-off values, age specific weight and height profiles (along with residence) of our study population presented in Table 3. More than $64 \%$ of married non-pregnant adolescent women weighed less than $45 \mathrm{~kg}$ and more than $15 \%$ height less than $145 \mathrm{~cm}$. Prevalence (\%) of low weight in MNPAW's is very high both at urban and rural areas in Bangladesh. Table 3 shows the decreasing pattern of prevalence (\%) of low height $(<145 \mathrm{~cm})$ as age increases.

Table 2: Group means of married non-pregnant adolescent women's weight and height by age at interview and residence, Bangladesh, 2004.

\begin{tabular}{|l|c|c|c|c|c|c|}
\hline \multirow{2}{*}{$\begin{array}{c}\text { Age at } \\
\text { interview }\end{array}$} & \multicolumn{3}{|c|}{ Weight (in kg) } & \multicolumn{3}{c|}{ Height (in cm) } \\
\cline { 2 - 7 } & Urban & Rural & National & Urban & Rural & National \\
\hline 13 & $41.8(n=7)$ & $41.4(n=24)$ & $41.5(n=31)$ & 147.1 & 148.9 & 148.5 \\
\hline 14 & $44.1(n=34)$ & $41.8(n=49)$ & $42.7(n=83)$ & 149.5 & 148.4 & 148.8 \\
\hline 15 & $44.7(n=59)$ & $42.5(n=109)$ & $43.2(n=168)$ & 149.9 & 150.3 & 150.2 \\
\hline 16 & $43.1(n=63)$ & $43.6(n=171)$ & $43.5(n=234)$ & 149.1 & 150.5 & 150.1 \\
\hline 17 & $43.1(n=83)$ & $43.1(n=211)$ & $43.1(n=294)$ & 150.6 & 150.6 & 150.6 \\
\hline 18 & $44.1(n=75)$ & $43.1(n=215)$ & $43.3(n=290)$ & 150.5 & 150.1 & 150.2 \\
\hline 19 & $44.1(n=104)$ & $43.8(n=239)$ & $43.9(n=343)$ & 149.8 & 150.7 & 150.5 \\
\hline Total & $43.8(n=425)$ & $43.2(n=1018)$ & $43.4(n=1443)$ & $\mathbf{1 4 9 . 9}$ & $\mathbf{1 5 0 . 3}$ & $\mathbf{1 5 0 . 2}$ \\
\hline
\end{tabular}

Note: The differences of means in weight by place of residence (urban and rural) is not statistically significant: $(p=$ 0.068) based on t-test.

Source: Author's calculation based on Bangladesh Demographic and Health Survey (BDHS)-2004.

Table 3: Percent distribution of married non-pregnant adolescent women by level of body weights, heights, age and residence, Bangladesh, 2004.

\begin{tabular}{|l|c|c|c|c|c|c|c|}
\hline \multirow{2}{*}{ Age } & \multicolumn{3}{|c|}{ Weight <45kg (\%) } & \multicolumn{3}{c|}{ Height <145cm (\%) } & Total \\
\cline { 2 - 7 } & Urban & Rural & National & Urban & Rural & National & no. \\
\hline 13 & 71.4 & 79.2 & 77.4 & 42.9 & 20.8 & 25.8 & 31 \\
\hline 14 & 52.9 & 67.3 & 61.4 & 14.7 & 22.4 & 19.3 & 83 \\
\hline 15 & 52.5 & 68.8 & 63.1 & 15.3 & 16.5 & 16.1 & 168 \\
\hline 16 & 68.3 & 64.9 & 65.8 & 19.0 & 12.9 & 14.5 & 234 \\
\hline 17 & 68.7 & 67.8 & 68.0 & 18.1 & 12.8 & 14.3 & 294 \\
\hline 18 & 61.3 & 66.5 & 65.2 & 10.7 & 18.6 & 16.6 & 290 \\
\hline 19 & 64.4 & 59.0 & 60.6 & 16.3 & 15.1 & 15.5 & 343 \\
\hline Total & $\mathbf{6 2 . 8}$ & $\mathbf{6 5 . 3}$ & $\mathbf{6 4 . 8}$ & $\mathbf{1 6 . 2}$ & $\mathbf{1 5 . 6}$ & $\mathbf{1 5 . 8}$ & $\mathbf{1 4 4 3}$ \\
\hline
\end{tabular}

Source: Author's calculation based on Bangladesh Demographic and Health Survey (BDHS)-2004.

Table 4: Distribution of married non-pregnant adolescent women by level of stunting* (height for age), Bangladesh, 2004.

\begin{tabular}{|l|l|c|c|}
\hline & Z scores & Percent & Number \\
\hline \multirow{3}{*}{ Stunting } & Above -2 SD (not stunted) & 50.4 & 727 \\
& Between -3SD to -2SD (moderately stunted) & 36.1 & 521 \\
& Below -3 SD (severely stunted) & 13.5 & 195 \\
\hline Total & & $\mathbf{1 0 0}$ & $\mathbf{1 4 4 3}$ \\
\hline
\end{tabular}

*Using CDC 2000 reference population.

Source: Bangladesh Demographic and Health Survey (BDHS)-2004. 
Table 5: Percent distribution of married non-pregnant adolescent women (MNAW) by level of stunting*, thinness and age, Bangladesh, 2004.

\begin{tabular}{|c|c|c|c|}
\hline Age & Stunted, \% (n) & Thin, \% (n) & Total number \\
\hline 13 & $25.8(8)$ & $00.0(0)$ & 31 \\
\hline 14 & $43.3(36)$ & $03.6(3)$ & 168 \\
\hline 15 & $38.7(65)$ & $12.5(21)$ & 234 \\
\hline 16 & $52.1(122)$ & $19.9(45)$ & 294 \\
\hline 17 & $39.4(116)$ & $15.6(46)$ & 290 \\
\hline 18 & $51.8(150)$ & $10.3(30)$ & 343 \\
\hline 19 & $63.8(219)$ & $26.8(92)$ & 1443 \\
\hline
\end{tabular}

Note: Figures in parenthesis indicate number of married non-pregnant adolescent woman.

*Using CDC 2000 reference population.

Source: Author's calculation based on Bangladesh Demographic and Health Survey (BDHS)- 2004.

Table 6: Trends in indicators of physical status for pregnancy of married non- pregnant adolescent women, Bangladesh, 1996-2004.

\begin{tabular}{|l|c|c|c|c|}
\hline Year & Weight <45kg (\%) & Height < 145cm (\%) & Stunted (\%) & Thin (\%) \\
\hline $1996 / 1997$ & 74.9 & 19.1 & 55.7 & 27.4 \\
\hline $1999 / 2000$ & 72.2 & 18.6 & 57.4 & 20.5 \\
\hline 2004 & 64.8 & 15.8 & 49.6 & 16.4 \\
\hline
\end{tabular}

Source: Author's calculation based on BDHS-1996/1997, BDHS-1999/2000, BDHS-2004.

\section{Stunting and thinness}

Age specific height and Body Mass Indexes are usually analyzed for making comparison with the Zscores (or SD) for stunting and percentiles for thinness in a well nourished reference population. Centers for Disease Control and Prevention (CDC) 2000 reference population data ${ }^{11}$ have been used for generating stunting and thinness profile of study population. The individual's Z-scores for study population are calculated as Z= (Observed value - Median reference value) / Standard deviation of reference population ${ }^{5}$.

Stunting: Chronic under nutrition leads to stunting in adolescence. Chronic under nutrition and consequently stunting is defined as Z-score of height for age $<-2 \mathrm{SD}$ of the reference population ${ }^{3,5}$. The index, stunting, is divided into three categories depending on the Z-scores: (i) not stunted (Z-score above -2 SD), (ii) moderately stunted (Z-score between -3 SD to -2 $\mathrm{SD})$, and (iii) severely stunted (Z-score below -3 SD).

Stunting among adolescents is important because about $25 \%$ of an individual's attained height is achieved during adolescence and forecasts that the end of growth in height and the attainment of adult height is getting closer $^{12}$. Stunted or short women are prone to have small pelvis and, are therefore, more likely to have prolonged labor during childbirth ${ }^{3,12}$. Studying stunting status of adolescent women (especially in developing countries, like Bangladesh) may help make nutritional program(s) to make future pregnancy outcomes safer. We applied the CDC 2000 reference population ${ }^{11}$ and compared the Z-scores of study population with the SD of the reference population for generating stunting profile of study population. Level of stunting of married non-pregnant adolescent women is provided in Table 4.

Table 4 shows that prevalence (\%) of stunting in our study population is very high. To look at the age specific stunting status of our study population we have presented the age specific stunting profile in Table 5. Table 5 exhibits increasing pattern of prevalence (\%) of stunting from age 17 to age 19 .

Thinness: Thinness results in poor pregnancy outcomes (miscarriage, preterm birth, stillbirth, etc), low birth weight (babies weight $<2500 \mathrm{gm}$ ) in particular, and is defined as Body Mass Index (BMI) less than $5^{\text {th }}$ percentile (of $\mathrm{BMI}$ ) of the reference population ${ }^{5}$. BMI is an anthropometry which depends on weight and height and is defined as body weight in kilograms $(\mathrm{kg})$ divided by height in meters $(\mathrm{m})$ squared $^{5}$ i.e. $\mathrm{BMI}=$ weight $(\mathrm{kg}) /$ height $\left(\mathrm{m}^{2}\right)$. We have applied the CDC 2000 reference population ${ }^{11}$ for generating thinness profile of study population (Table 5). The prevalence (\%) of thinness of 
study population between ages 16 and 18 years peaked at age 16 years (19.9\%) and again reached in $26.8 \%$ at age 19 years.

\section{Trends in indicators of physical status for pregnancy}

Trends in indicators of physical status for childbearing of married adolescent women in Bangladesh can be examined by making time series of estimates of those indicators using BDHS data beginning from 1996. For estimating four indicators - prevalence (\%) of low weight, prevalence (\%) of low height, prevalence (\%) of stunted, prevalence (\%) of thinness - of MNPAW in various years, same procedures, as before, have been used. Indicators of physical status for childbearing in different years are provided in Table 6 .

Table 6 shows that the indicators of physical status for pregnancy have improving pattern from the year 1996 to year 2004. This may reflect the result of effort put into community health through the country's Health and Population Sector Program (HPSP) initiated in 1998 and Health Nutrition and Population Sector program initiated in 2003.

\section{Conclusion}

The study indicated that at least $60 \%$ of married non-pregnant adolescent at all ages (13-19) have poor weight and about $15 \%$ are short and are not physically fit for pregnancy and may be responsible for high maternal mortality and infant morbidity and mortality in Bangladesh. So it is necessary to encourage married adolescent women to delay childbearing through community education and by encouraging them to use family planning services. Nearly $50 \%$ of our study population is stunted meaning that half of married nonpregnant adolescent women are undernourished and it has increasing pattern as age increases. It should be necessary to pay special emphasizes for improving adolescent women's nutritional status through the country's Health, Nutrition and Population Sector Program or through National Nutrition Program (NNP).

It should be emphasized that awareness building programs regarding late entrance into marriage for adolescent girls in Bangladesh may be helpful as long term intervention(s) for reducing maternal and infant morbidity and mortality.

Acknowledgment: Almost of this study has been conducted in my stay (during MS in Demography studies) at Center for Northeast Asian Studies (CNAS) of Jilin University, China. I am grateful to CNAS for providing me good research environment.

\section{Funding: None \\ Conflict of Interest: None}

\section{References}

1. Islam M. M. and Mahmud M. "Marriage Pattern and Some Issues Related to Adolescent Marriage in Bangladesh", Asia-Pacific Population Journal, 1996; Vol. 11, No. 3. pp 27-42.

2. NIPORT (National Institute of Population Research and Training) [Bangladesh], Mitra and Associates, and ORC Macro. "Bangladesh Demographic and Health Survey 2004”, Dhaka, Bangladesh: National Institute of Population Research and Training, Mitra and Associates and Calverton, Maryland, USA: ORC Macro; 2005.

3. World Health Organization (WHO). Adolescent nutrition: A Review of the Situation in Selected South- East Asian Countries. Regional Office for South-East Asia, New Delhi. WHO. 2006.

4. World Health Organization (WHO). Maternal Mortality: A Global Factbook. Geneva. WHO. 1991.

5. World Health Organization (WHO). "Adolescents" at: WHO Physical Status: The Use and Interpretation of Anthropometry. Report of a WHO Expert Committee. WHO technical report series no. 854. Geneva. WHO. 1995.

6. Hofmeyr GJ. Obstructed labor: using better technologies to reduce mortality. International $J$ Gynecol Obstetr. 2004;85:s62-s72.

7. NIPORT (National Institute of Population Research and Training), ORC Macro, Johns Hopkins University and ICDDR, B. Bangladesh Maternal Health Services and Maternal Mortality Survey 2001. Dhaka, Bangladesh and Calverton, Maryland (USA): NIPORT, ORC Macro, Johns Hopkins University and ICDDR, B. 2003.

8. Save the Children. State of the World's Mothers 2004: Children Having Children, Westport, CT, USA. Save the Children. [updated May 2004; cited July 2010] Available from http://www.savethechildren. org/publications/mothers/2004/SOWM_2004_final. pdf. 
9. Ikamari L.D.E. "The effect of education on the timing of marriage in Kenya", Demographic Research 2005;12:1-28.

10. Mayor S. Pregnancy and childbirth are leading causes of death in teen age girls in developing countries. Br Med J 2004;328:1152.

11. Kuczmarski RJ, Ogden CL, Guo SS, Grummerstrawn LM, Flegal KM, Mei Z, Wei R, Curtin LR,
Roche AF, Johnson CL. 2000 CDC growth charts for the United States: Methods and development. National Center for Health Statistics. Vital health Stat. 2002;11(246):1-190.

12. Kurz K. M. Adolescent nutritional status in developing countries. Proc Nutr Soc 1996;55:32131.

\section{How to cite this article?}

Haque MN. Anthropometric Assessment for Adolescent Pregnancy: A Descriptive Study on Married Aadolescents in Bangladesh. J Nep Paedtr Soc 2010;30(3):154-159. 